\title{
The development of an innovative ecophotonics/illumination engineering education program for grades 6-12
}

Constance Walker, Stephen Pompea, Robert Sparks

Constance E. Walker, Stephen M. Pompea, Robert T. Sparks, "The development of an innovative ecophotonics/illumination engineering education program for grades 6-12," Proc. SPIE 8481, Optics Education and Outreach II, 84810E (18 October 2012); doi: 10.1117/12.930273

SPIE Event: SPIE Optical Engineering + Applications, 2012, San Diego, California, United States 


\title{
The Development of an Innovative Ecophotonics/Illumination Engineering Education Program for Grades 6-12
}

\author{
Constance E. Walker ${ }^{a}$, Stephen M. Pompea ${ }^{a}$, Robert T. Sparks ${ }^{a}$ \\ ${ }^{a}$ National Optical Astronomy Observatory, 950 N. Cherry Avenue, Tucson AZ USA 85719
}

\begin{abstract}
The National Optical Astronomy Observatory's Education and Public Outreach Group has created pedagogically-sound science enrichments programs for grades 6-12 that embed both active and problem-based learning in the areas of ecophotonics and illumination engineering. Recently, we have added film clips from the award winning film 'The City Dark' as introductory material to our program materials. This feature documentary is about light pollution and the disappearing night sky. The use of the film clips helps students better visualize the growing problems associated with light pollution. An outline of the usage of the film clips is presented with NOAO-designed activities and kit materials. The goal of the activities is to help familiarize students with the problems and solutions to light pollution. In particular, the use of responsible lighting through progressive illumination engineering practices to solve this global problem is discussed.
\end{abstract}

Keywords: optics education, illumination engineering, eco-photonics, technology education, outreach

\section{INTRODUCTION}

The National Optical Astronomy Observatory's Education and Public Outreach Group has created pedagogically-sound and independently evaluated science enrichment programs for K-12 that embed both active and problem-based learning in the areas of eco-photonics and illumination engineering. As launching points into activities and fodder for later discussion, film clips are incorporated from The City Dark, an award-winning, feature documentary about light pollution and the disappearing night sky. The educational program goal is to address this global eco-photonics challenge with responsible illumination engineering. An outline of the usage of the film clips is presented with activities, kit materials, and pedagogical justification for their scope and sequence. The activities and kit have been used in dozens of teacher workshops and with students during 75 environmental center outreach sessions (Figure 1). ${ }^{1,2}$ We will also present future plans for dissemination.

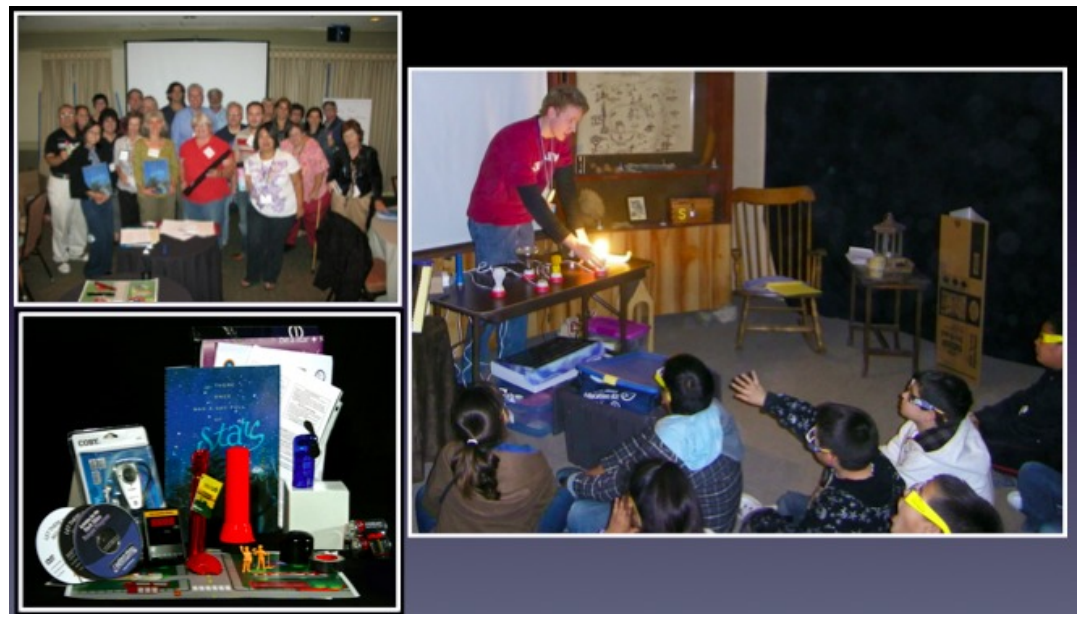

Fig. 1. Examples of the Dark Skies Education program at the National Optical Astronomy Observatory: a teacher training workshop, an evening session with students and the kit. 


\section{MOTIVATION}

\subsection{Light Pollution Wastes Energy}

About one-third of outdoor lighting escapes unused into the sky according to the International Dark-Sky Association ${ }^{3}-$ wasting energy, washing out the night sky, harming the habits and habitats of many wildlife species and adversely affecting our health (Figures 2 and 3 ).

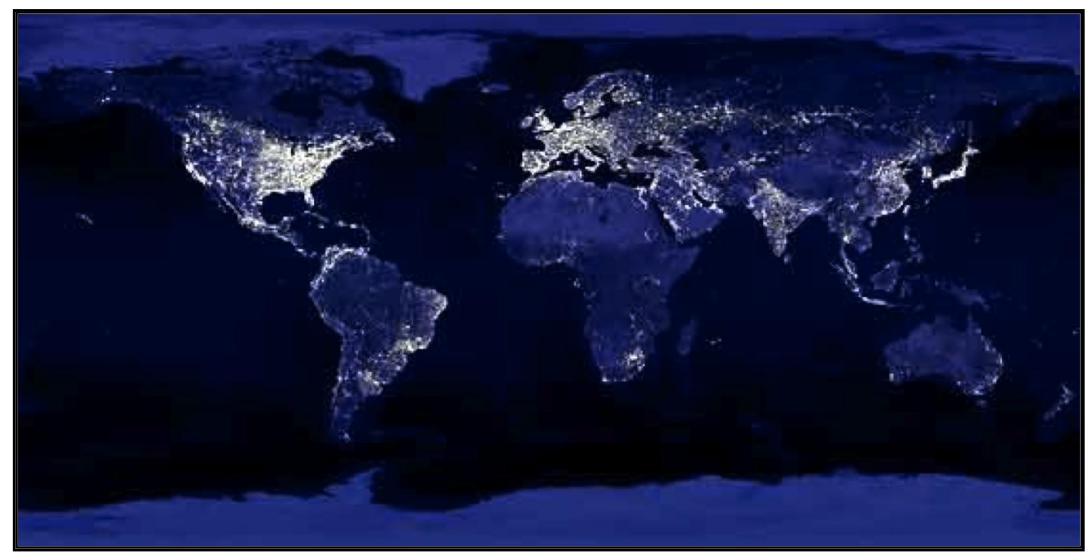

Fig. 2. The image of the world at night was taken by the Defense Meteorological Satellite Program and illustrates the upward directed light from the Earth.

\subsection{Light Pollution Affects Our View of a Starry Night Sky}

About 63 percent of the world's population and 99 percent of the population in the European Union and continental United States live in areas where the night sky is above the threshold set for polluted status. ${ }^{4}$

\subsection{Light Pollution affects Wildlife}

It is estimated that at least 100 million birds are killed annually due to collisions with manmade structures, which include wind turbines, power lines, glass and towers. Collisions due to urban light represent approximately one third of all collisions, while two thirds of collisions occur during the daytime. 90,000 birds are killed flying into buildings in New York City alone. ${ }^{5}$

\subsection{Light Pollution affects Health}

With 20 years of study, medical researchers have concluded that light at night increases the incidence of certain cancers, most notably breast cancer. Dr, Mario Motta, on the Council of Science and Public health of the AMA, says, "Researchers now estimate that up to $30 \%$ of breast cancers are secondary to light at night suppressing circadian rhythm. The research basis for this conclusion has become so compelling that the International Agency for Research on Cancer recently declared circadian-rhythm disruption as a class $2 \mathrm{~A}$ carcinogen - placing it on the same level of severity as the effects of tobacco smoke on lung cancer.", 


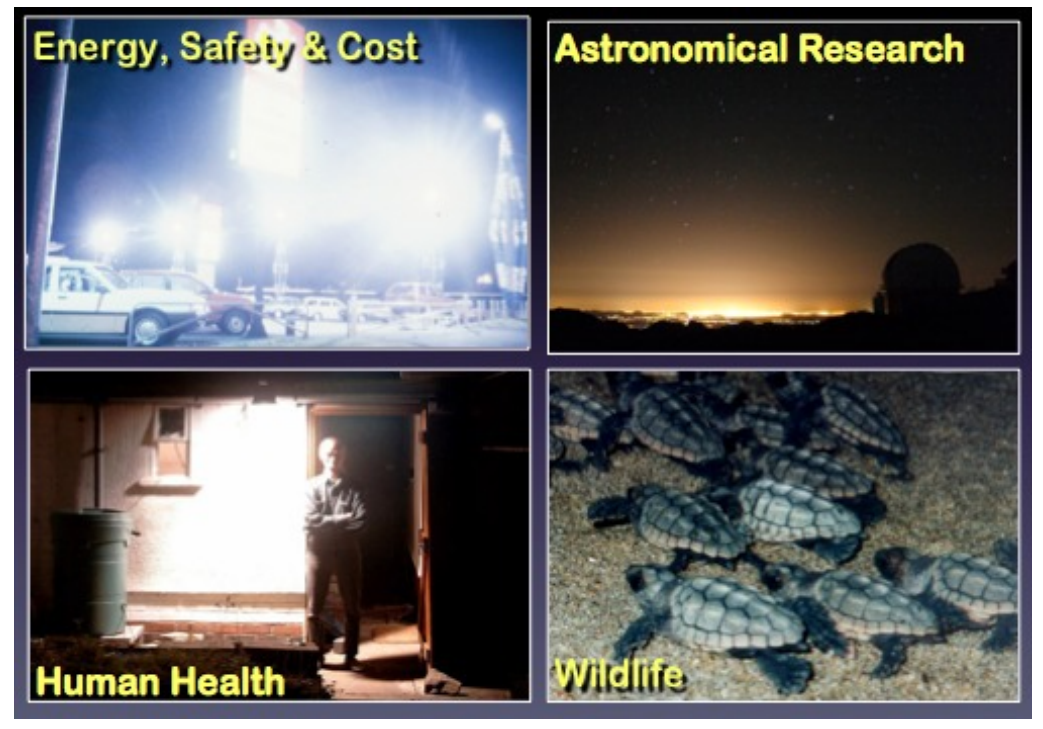

Fig. 3. Four areas of peoples' lives (energy consumption, health, wildlife and our ability to see a starry night sky) are affected by light pollution.

\subsection{Addressing the Challenge}

The issue surrounding light pollution is a global ecophotonics challenge that affects everyone, but that can be addressed with responsible illumination engineering and better lighting practices. The challenge is that with over half the world's population living in cities (where most of the light pollution originates), how do you explain to city people what they are missing and what light pollution is affecting, if they have never seen a pristinely dark night sky?

To address this challenge, the National Optical Astronomy Observatory has created extensive educational programs and resources for a wide variety of audiences on the public understanding of the issues surrounding light pollution. Two of the programs highlighted in this article are the GLOBE at Night and Dark Skies Rangers programs. These are the heart of the educational programs used in schools to educate tomorrow's stewards of the Earth on light pollution issues. "The City Dark" film documentary added to the programs' introduction provides the essential hook to entice students' interest.

\section{THE CITY DARK}

The City Dark $^{7}$ is a feature documentary about light pollution and the disappearing night sky. It premiered in competition at the 2011 South by Southwest Film Festival, where it won the Jury Prize for Best Score/Music. The City Dark won the Grand Jury Prize at the Environmental Film Fest at Yale and was selected as a New York Times Critics' Pick (Figure 4). Posing a deceptively simple question - "What do we lose when we lose the night?"- the film leads viewers on a quest to understand how light pollution affects people and the planet. The film introduces viewers to the issue of wasted uplight (and therefore wasted expense), the increased breast cancer rates from exposure to light at night, the effects of light pollution on the habitats of wildlife, and the impact of light pollution on a generation of children with a limited view of the universe. Clips of the film will be used to capture the interest of the students at the beginning of activities such as the light shielding demonstration, the spectra of lights activity, the turtle hatching role play activity, and the outdoor lighting audits. 


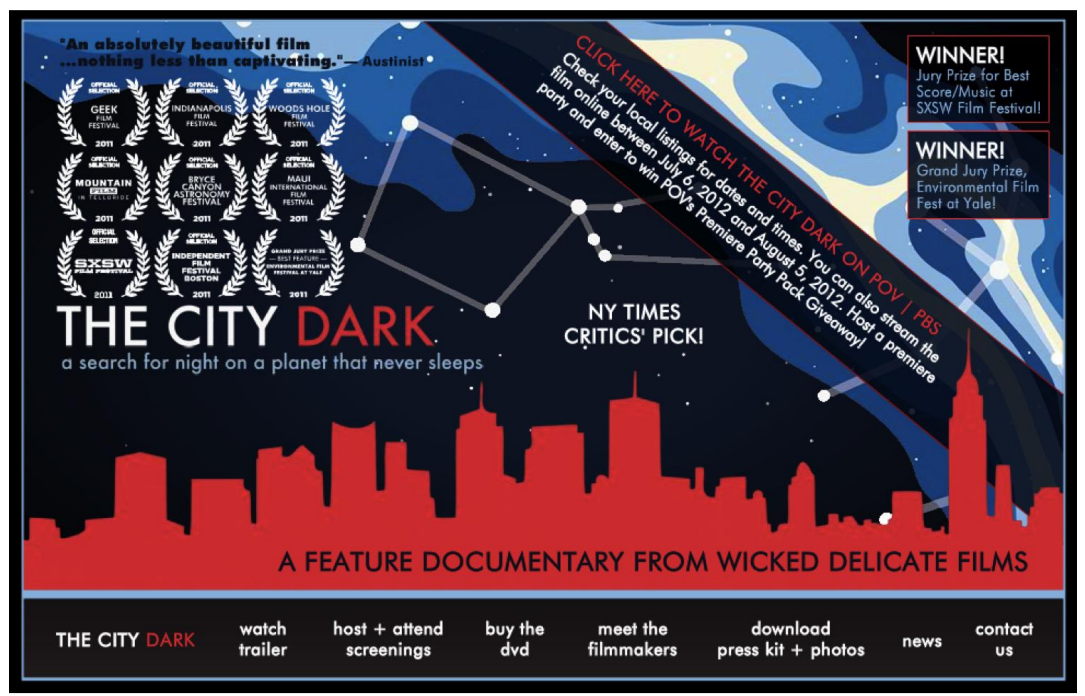

Fig. 4. "The City Dark" (Video 1) is a film documentary that leads viewers on a quest to understand how light pollution affects people and the planet: http://my.docuseek2.com/citydark/. (Image is from www.thecitydark.com.)

\subsection{An Invitation to Dialog}

The City Dark can be framed as an invitation to an age-appropriate dialog on the main issues surrounding light pollution and provide a transition into the "Dark Skies Rangers" activities. Discussion can also be intentionally crafted to help a wide range of audiences think more deeply about issues in the film. In addition to middle and high school students, the audiences could include astronomy or environmental clubs, youth organizations, community groups, amateur astronomy clubs, professional societies, planetaria, museums, nature centers, science centers, libraries, observatories, as well as others.

A discussion of light pollution can be a launching pad into multiple topical areas:

- Astronomy

- Biology

- Cancer

- Chronobiology

- Cosmology

- Conservation

- Criminology

- Eco-photonics

- Energy

- Environment

- Green Building

- Health
- Illumination Engineering

- Lighting design

- Nature

- Ornithology

- Philosophy

- Public Safety

- Science

- Spirituality

- Stargazing

- Sea Turtles

- Urban Planning

- Wildlife

\section{ISSUES PRESENTED IN THE FILM}

There are six topical areas into which the 52-minute version of the film documentary is divided. Each topical area is less than 11 minutes long, a length of time conducive to the typical attention span of high school and middle school students. Each of the topical areas provides a good introduction for an ensuing discussion, which in turn provides a good transition into the activities that follow. (See Table 1.) The film documentary is downloadable for classroom use at http://my.docuseek2.com/citydark/. 
Table 1. Topical areas of the film.

\begin{tabular}{|c|l|l|l|}
\hline $\begin{array}{l}\text { Area of } \\
\text { Film }\end{array}$ & Title of Area & $\begin{array}{l}\text { Start } \\
\text { Time }\end{array}$ & Description \\
\hline $1^{\text {st }}$ & The City Bright & $\begin{array}{l}3 \mathrm{~min} \\
15 \mathrm{sec}\end{array}$ & $\begin{array}{l}\text { "The City Bright" portrays the growth of artificial } \\
\text { lights over the last 100 years. }\end{array}$ \\
\hline $2^{\text {nd }}$ & Islands of Dark & $\begin{array}{l}13 \mathrm{~min} \\
57 \mathrm{sec}\end{array}$ & $\begin{array}{l}\text { "Islands of Dark" discusses the effects of light } \\
\text { pollution on astronomy. }\end{array}$ \\
\hline $3^{\text {rd }}$ & $\begin{array}{l}\text { Nature and the } \\
\text { Night }\end{array}$ & $\begin{array}{l}21 \mathrm{~min} \\
35 \mathrm{sec}\end{array}$ & $\begin{array}{l}\text { "Nature and the Night" discusses the effects of } \\
\text { light pollution on wildlife. }\end{array}$ \\
\hline $4^{\text {th }}$ & Night's Shift & $\begin{array}{l}31 \mathrm{~min} \\
5 \mathrm{sec}\end{array}$ & $\begin{array}{l}\text { "Night's Shift" discusses the effects of light } \\
\text { pollution on health. }\end{array}$ \\
\hline $5^{\text {th }}$ & Why We Light & $\begin{array}{l}40 \mathrm{~min} \\
8 \mathrm{sec}\end{array}$ & $\begin{array}{l}\text { "Why We Light" discusses outdoor lighting and } \\
\text { its relation to crime levels. }\end{array}$ \\
\hline $6^{\text {th }}$ & Astrofilia & $\begin{array}{l}44 \mathrm{~min} \\
30 \mathrm{sec}\end{array}$ & $\begin{array}{l}\text { "Astrofilia" discusses ways in which light } \\
\text { pollution \& energy consumption can be reduced. }\end{array}$ \\
\hline
\end{tabular}

\section{THE DARK SKIES RANGERS ACTIVITIES AND KIT}

To introduce students in grades 6 through 12 to energy-responsive design principles, staff at the National Optical Astronomy Observatory have carefully crafted a focused, sequential, and cumulative set of learning experiences. These learning experiences, along with materials for a shielding demonstration (Figure 5), are part of a Dark Skies Education Kit (Figure 1). The first of the four learning experiences is the light shielding demonstration. It provides a visual illustration of the causes of light pollution and introduces the main vocabulary that relates to illumination engineering. The second learning experience is the "Spectra of Lights" activity (Figure 5). While the "Light Shielding Demonstration" reveals how shielding a street-light can save energy, the primary goal of the "Spectra of Lights Demonstration" is to show how the energy efficiency of a specific type of lamp, as well as the lamp's appropriate lighting role, is related to the lamp's spectral and physical properties. It also helps in the "Outdoor Lighting Audit" to explain the need for energy efficient bulbs. The third learning experience is the school or home "Outdoor Lighting Audit", which has students perform an audit, calculate the energy, cost and carbon footprint consumed, produce a revised master plan by retrofitting with compliant lighting, and recalculate with good lighting to see how much is saved. They then report on their results to a school board or city council. The solutions rely on an understanding of illumination engineering principles.

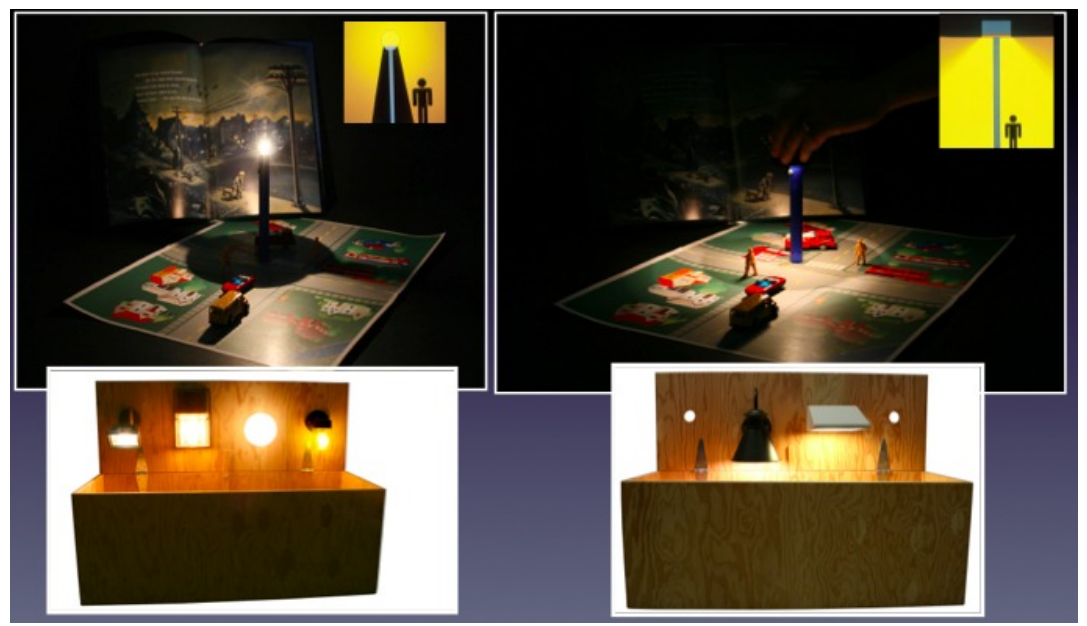

Fig. 5. The top frames show "Light Shielding Demonstration" before and after the "streetlight" is shielded. Examples of bad and good lighting fixtures (bottom frames) are used in the "Spectra of Lights" activity. 
The fourth scaffolded learning experience is the "GLOBE at Night" light pollution assessment campaign. ${ }^{8}$ This capstone activity provides an opportunity for more global awareness of the importance of remedying light pollution issues. Citizen-scientists record the brightness of the night sky by visually matching the appearance of a constellation like Orion with star maps of progressively fainter stars or using meters to obtain more precise measurements. Measurements are submitted on-line and resulting maps of all worldwide observations are created. Over the last 7 years of 10 day GLOBE at Night campaigns, 83,000 measurements have been contributed from over 115 countries. (See www.globeatnight.org.)

The learning experiences can be used separately, but together they provide an integrated learning unit. ${ }^{1,2,3}$ In addition to these four experiences, there are other Dark Skies Rangers activities like the one that has students role-playing sea turtles. This activity works favorably on students in middle school (and younger). Typically it is done after the introduction to vocabulary in the light shielding demonstration. Students understand after the first round why sea turtles do not make it into the ocean due to the lights on shore. In the second round, corrective solutions to the lights on shore are implemented, and more sea turtles survive.

\section{SOME DISCUSSION PROMPTS AS LEAD-INS FROM FILM TO ACTIVITIES}

PBS offers a "Community Engagement and Education" discussion guide for "The City Dark". The questions associated with four of the six sections of the film documentary are geared more toward adults. However, the ideas they embody can be adapted to middle and high school students. In addition, PBS offers a lesson plan for the effect of light pollution on sea turtles called "Which Way to the Ocean?"' The lesson plan comes complete with objectives, materials needed (3 film clips), an activity, extensions, resources (books, websites, etc) and standards. The guide (downloadable as a pdf file from the same webpage) also provides quotes, suggestions for taking action and synopses of all 6 sections of the film. All of these can set a foundation for discussion questions as well as a lead-in to the Dark Skies Rangers activities found at http://www.globeatnight.org/dsr/.

\subsection{The City Bright}

After seeing the 10.5-minute clip on "The City Bright", ask the students what are some of the lights they remember seeing in the clip? Set up the Spectra of Lights activity and discuss with the students the different types of lights, their spectra (using diffraction gratings) and their efficiency (Figure 6a).

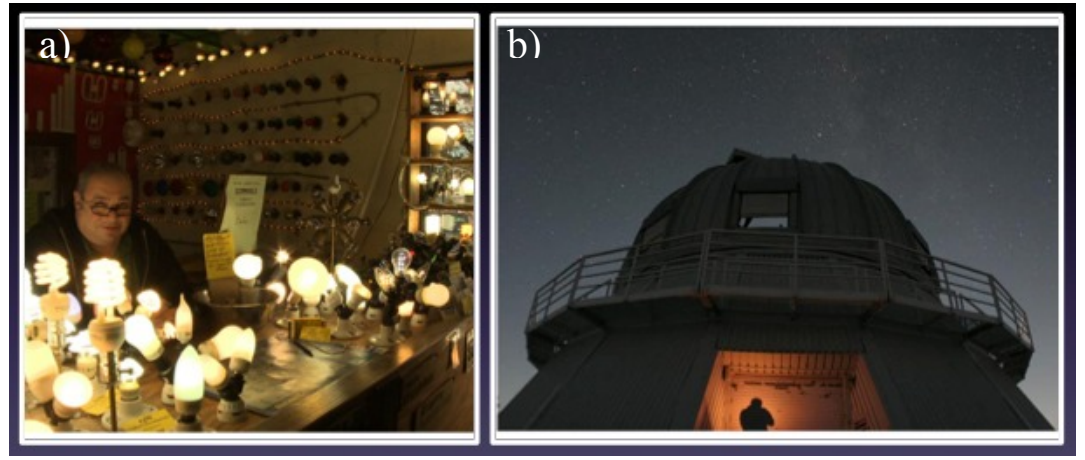

Fig. 6. a) The first area the film discusses is "The City Bright", the growth of artificial lights. b) The second area is called "Islands of Dark" on the effects of light pollution on astronomy. (Photos from "The City Dark" film documentary.)

\subsection{Islands of Dark}

After seeing the 7.5-minute clip on "Islands of Dark", use the Light Shielding Demonstration to ask students, "What do you notice about the stars when the light is on without a shield, when the light is on with a shield and when the light is off?" (Figure 6b).

Ask high school students, "Our first questions about the universe can be traced when people first looked up at the sky. Every civilization since then built science around explaining a sky they could see at night. If we are not ever able to see the stars at night, do you think we would lose our ability to see beyond ourselves?" 


\subsection{Night's Shift}

After seeing the 10.5-minute clip on "Night's Shift", ask students, "The American Medical Association recently officially stated that frequent use of nighttime lighting disrupts our natural night and day cycle among other things and so creates what could be harmful effects on our health, ranging from not being able to sleep to being more likely to get cancer. What can we do to prevent that from happening?" (Figure 7a)

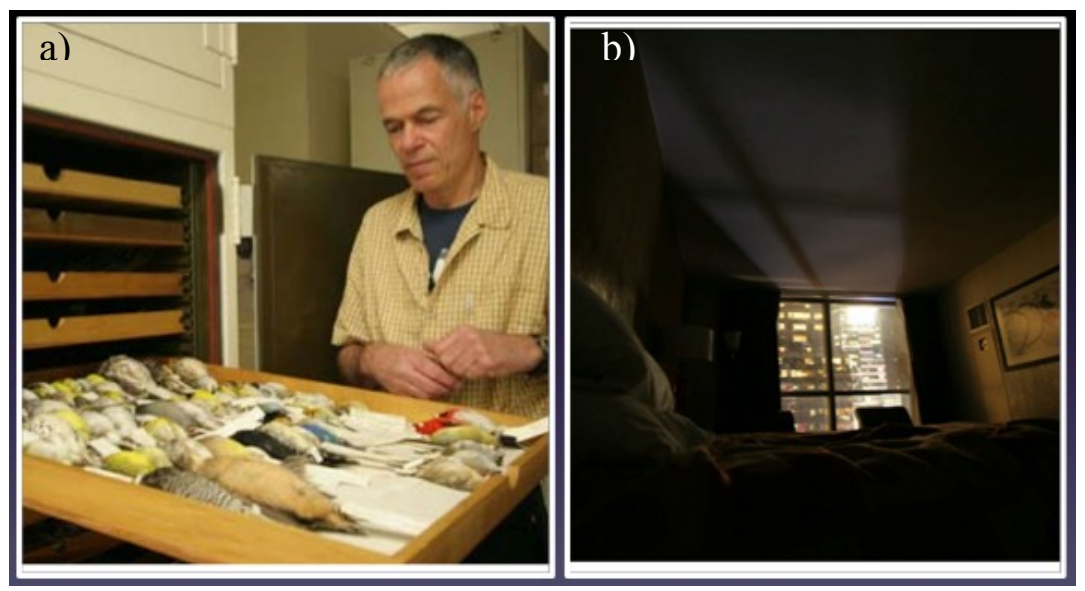

Fig. 7. a) The third area the film discusses is "Nature and the Night", the effects of light pollution on ecology. b) The fourth area is called "Night's Shift" on the effects of light pollution on health.

\subsection{Nature and the Night}

After seeing the 10-minute clip on "Nature and the Night", ask students, "Since lights disorient wildlife or disrupt the natural cycles that allow them to survive and reproduce (e.g., the turtles in Florida or birds in Chicago), what would you recommend we do to prevent that from happening?" (Figure 7b)

For middle school students (or younger), follow up with the "On the Night You Hatched" activity in which the students role-play sea turtles or with "Do They See the Light" in which students experiment with how light pollution affects insects.

\subsection{Why We Light and Astrophilia}

After seeing the 3.5-minute clip on "Why We Light" and the 7.5-minute clip on "Astrophilia", ask students "If you couldn't shut off the outdoor lights for safety reasons, what could you do to prevent the light from going up into space where it is wasted?" (Figure 8) Go over the different types of light pollution (sky glow, light trespass and glare).

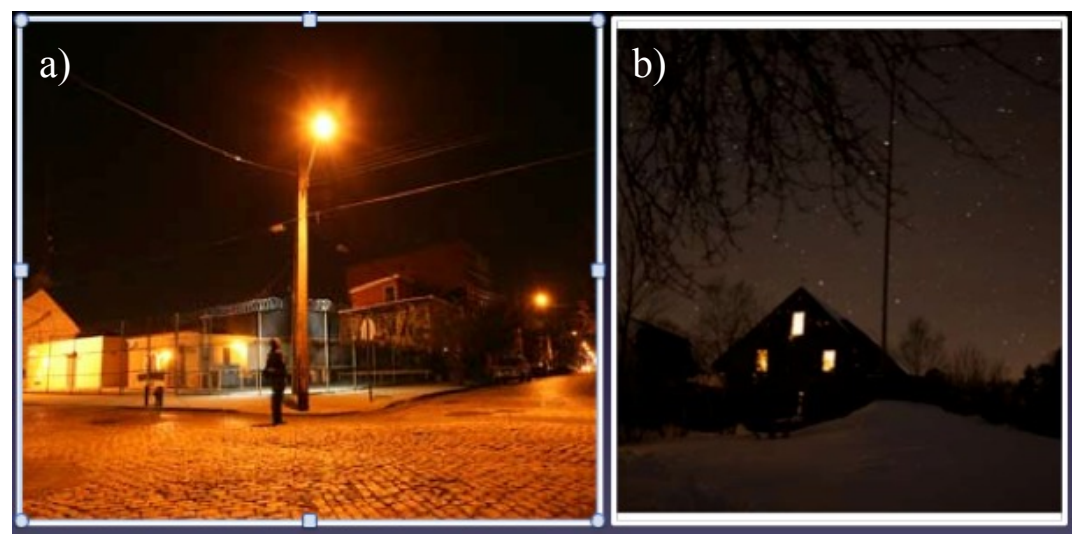

Fig. 8. a) The fifth area the film discusses "Why We Light" and is on light and crime. b) The sixth area is called "Astrophilia" and is on reducing light pollution and energy consumption. 
Ask experts such as an astronomer, a wildlife biologist, a medical doctor, an energy consultant, and a law-enforcement individual, to attend the respective discussion to enhance it with their experiences. (See the Dark Skies Rangers activity called "Student Symposium".)

\subsection{After the Film}

When the 52-minute film documentary is done, hand out the "Outdoor Lighting Audit" either as a school project or a homework assignment over the next couple of days.

Subsequently, when the GLOBE at Night campaign is approaching during any, some or all of the first five months of the year, use the "How Light Pollution Affects the Stars" activity to help them understand the concept of stellar magnitude and the "Constellation at Your Fingertips" activity to help them visualize the constellation used in the campaign. (See http://www.globeatnight.org/dsr/.)

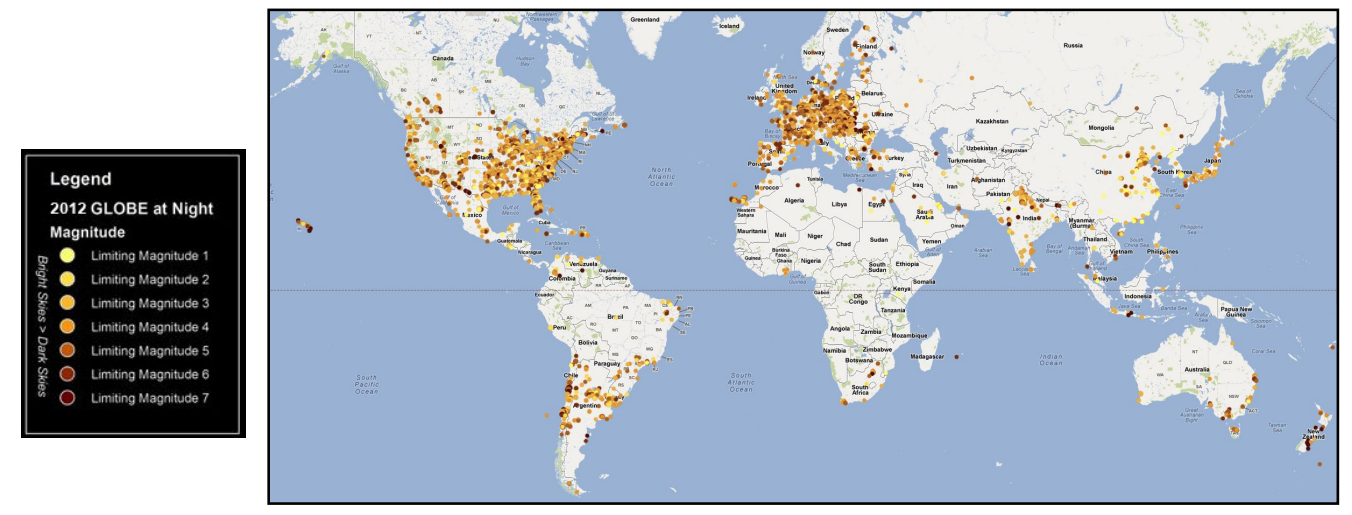

Fig. 9. The results from the worldwide GLOBE at Night 2012 light pollution measurement campaign. The lighter the dot, the brighter the night sky; the darker the dot, the darker the night sky. Units are in stellar magnitudes.

Both the "Outdoor Lighting Audit" and the GLOBE at Night campaign can lead into a discussion of local lighting ordinances, as featured in "Astrophilia", the last film clip. Data from the GLOBE at Night campaign (Figure 9) can also provide the material with which to do research projects on the comparison of data over time (changes, trends), the comparison to population density data and maps, searching for potential dark sky oases sites in cities, monitoring of lighting ordinance compliance, correlating the effects of light pollution on animals or plants, effects on human health and the assessment of wasted energy and energy costs.

\section{AN EXAMPLE OF EDUCATIONAL EVENTS USING THE FILM}

In March 2012, the Honors College at the University of Arkansas in Fayetteville brought documentary filmmaker, Ian Cheney, and one of the authors (CEW) to campus, for a two days of discussions and the largest-ever audience for a screening of Cheney's award-winning film, "The City Dark".

\subsection{First Day: an Informal Discussion at a Restaurant and Starparty}

Events began with a Sunday night discussion in a restaurant downtown that drew a diverse group of faculty, students and community members from all walks of life, including farmers, artists, campus planners and developers. As a science education specialist at the National Optical Astronomy Observatory and director of GLOBE at Night, Walker launched a discussion using the light shielding demonstration. A flashlight was positioned as a streetlight at the center of a miniature mockup of a cityscape; a second flashlight was the light source for an ad-hoc planetarium box with holes punched through it. No "stars" appeared on the ceiling. Then, when Walker shielded the "streetlight" with a cap, pricks of light appeared on the ceiling above, demonstrating that streets could be safely lit while keeping stars visible. Issues around saving energy and money and directing light when and where you need it were addressed.

A lively discussion of ongoing efforts to preserve the night sky in Northwest Arkansas ensued, and the evening concluded outdoors. Although cloudy skies cancelled the star party that had been planned, Walker demonstrated how to participate in GLOBE at Night using its smart phone web application, and participants measured light pollution in downtown Fayetteville using a handheld brightness meter (Figure 10). 


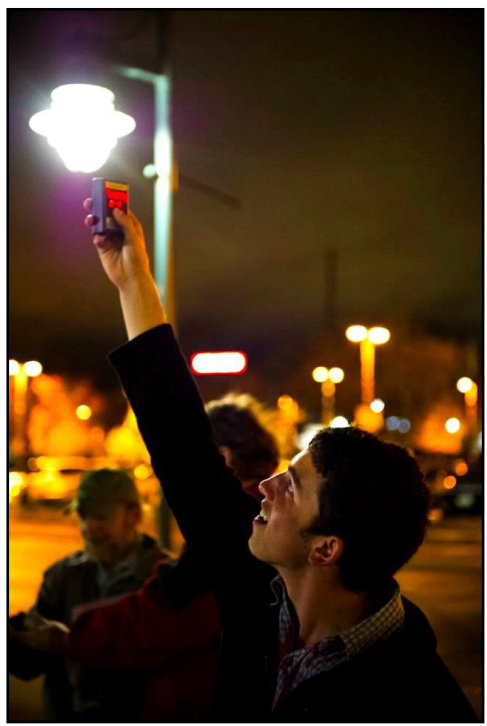

Fig. 10. A student from the University of Arkansas learns to use the Sky Quality Meter (by Unihedron) to measure the night sky brightness in Fayetteville.

\subsection{Second Day: a Classroom Presentation and the Film Screening}

On Monday, Cheney and Walker discussed light pollution with more than 200 students in the Fundamentals of Sustainability course led by professor Steve Boss. Walker coupled discussion with a number of actions students could take to address the issue. A lunch with select faculty from across campus followed. Events were capped by the screening of "The City Dark". More than 500 attended the screening and the panel discussion with Cheney and Walker that followed, the largest ever turnout for a screening of the film (Figure 11).

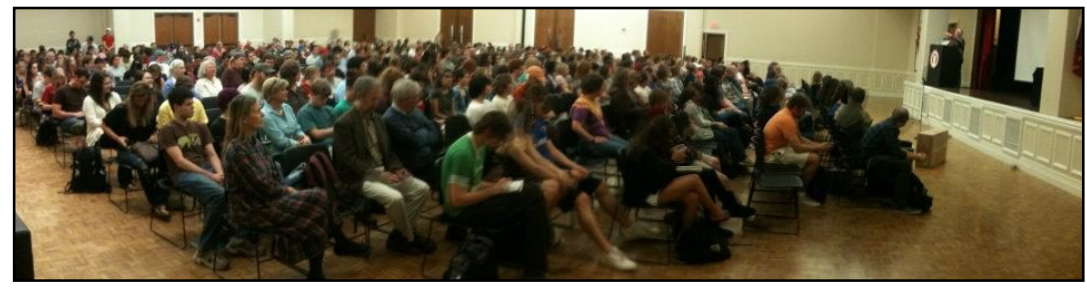

Fig. 11. The showing of "The City Dark" at the University of Arkansas to 500 people.

\subsection{Aftermath}

As a follow up to these events, Boss identified a grid of 25 Northwest Arkansas streets, roads, and highways that his students and other members of the community adopted for the GLOBE at Night to take light readings during the campaigns (Figure 12). The grid of measurements will provide data that will support future research on the impact of Fayetteville's outdoor lights on wildlife, health, energy consumption and cost. 


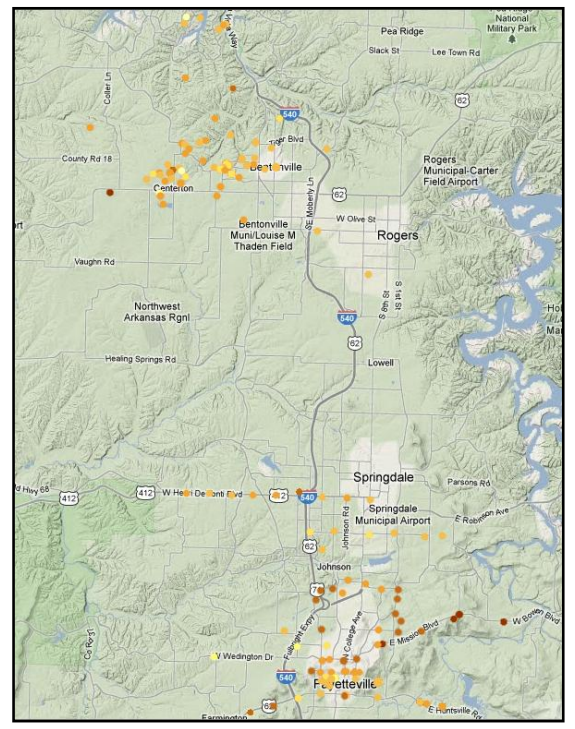

Fig. 12. The 2012 GLOBE at Night map of Fayetteville and Bentonville, Arkansas. It follows the same legend as in Figure 9.

\section{NEXT STEPS}

The National Optical Astronomy Observatory's Education and Public Outreach Group recently received a new grant from the Arizona Public Service Company for developing activities on energy conservation that utilize iPads in the classrooms of 20 middle school teachers in Yuma, Arizona. All of the Dark Skies Rangers activities, information on the GLOBE at Night campaign (and its data), and The City Dark film documentary will be placed on iPads. iPads will be used during in-situ workshops to gain access to materials and between workshops to communicate with teachers and students with the iPad's Facetime tool. Plans are to use materials like The City Dark film documentary with the Dark Skies Rangers activities as outlined in Section 6. Initial teacher training workshops and classroom visits will get teachers and students comfortable with concepts, activities and projects. The Facetime follow-ups will occur regularly each month during the academic year. The culminating event will be a form of assessment at a Family Night, where students will present their projects. Projects could involve The City Dark, outcomes of the Outdoor Lighting Audit or the Student Symposium or results from the GLOBE at Night campaign, to name a few. After an evaluation of the program from an external evaluator, the program will be improved and disseminated to the communities that surround NOAO's southern observatory in Chile. Dark Skies Rangers activities and GLOBE at Night webpages will be translated into Spanish this coming year; subtitles for The City Dark are being considered. With the translations accomplished, additional Spanish speaking countries will be able to benefit from the program and The City Dark, as well.

\section{REFERENCES}

[1] Walker, C. E., Pompea, S. M., Sparks, R. T. and Dokter, E., "Teaching illumination engineering using light pollution education kits" in Optics Education and Outreach, edited by G. Groot Gregory, Proc. SPIE 7783 (2010).

[2] Walker, C. E. and Pompea, S. M., "National Education Program for Energy Efficient Illumination Engineering," in EcoPhotonics, Proc. SPIE 8065 (2011).

[3] B. Parks (private communication).

[4] Chepesuik, R., "Missing the Dark: Health Effects of Light Pollution.” Environmental Health Perspectives, (2009).

[5] American Bird Conservancy, http://www.abcbirds.org/abcprograms/policy/collisions/index.html (2010).

[6] Motta, M., "Medical Effects of Light Polllution", Global Astronomy Month Dark Skies Awareness blog, http://www.astronomerswithoutborders.org/gam2012/gam-darksky-blog/1137-medical-effects-of-lightpollution.html (2012).

[7] http://www.thecitydark.com 
[8] Walker, C. E. and Pompea, S. M., "Global campaign to save energy and fight light pollution", in the SPIE Newsroom, http://spie.org/x42167.xml?highlight=x2408\&ArticleID $=x 42167$ (2010).

[9] http://www.pbs.org/pov/citydark/lesson_plan.php

[10] Curlee, K. A., "Bright Lights, Big City ... No Stars?", University of Arkansas Honors College magazine, (2012). 